\title{
Postoperative respiratory depression associated with pregabalin: A case series and a preoperative decision algorithm
}

\author{
Naveen Eipe MBBS MD, John Penning MD FRCPC
}

\begin{abstract}
N Eipe, J Penning. Postoperative respiratory depression associated with pregabalin: A case series and a preoperative decision algorithm. Pain Res Manage 2011;16(5):353-356.

Pregabalin is gaining popularity in the perioperative period for its usefulness in treating neuropathic pain and its apparent opioid-sparing effect. The present report describes the perioperative course of three patients who received pregabalin and experienced significant respiratory depression in the postoperative period. All three patients consented to the report and publication of the present case series. The first patient was elderly with borderline renal dysfunction. She experienced respiratory arrest in the immediate postoperative period following a craniotomy for tumour excision. The second patient presented with severe respiratory depression $12 \mathrm{~h}$ after receiving a spinal anesthetic for joint replacement, and was later found to have clinically significant obstructive sleep apnea. The third patient, who was an otherwise healthy elderly individual on benzodiazepines for anxiety, experienced respiratory arrest in the postanesthesia care unit after an uneventful anesthesia for lumbar spine decompression. All of these patients were treated successfully with standard resuscitation measures. Although other causes of respiratory depression in these patients were considered, there appears to be an association between pregabalin and this complication. The present article briefly reviews the evidence regarding the perioperative use of pregabalin. Based on the authors' experience and the available evidence, they believe that pregabalin may be useful in the management of acute pain in carefully selected patients undergoing certain surgeries. A clinical algorithm has been developed to guide the perioperative use of pregabalin. This algorithm may be helpful in increasing the safety of perioperative pregabalin use.
\end{abstract}

Key Words: Pain - acute pain service, postoperative, multimodal analgesia; Multimodal analgesia-opioids, naloxone, pregabalin; Pregabalin-complications, sedation, respiratory depression, evidence, algorithm; Algorithm - indications, contraindications and dose adjustment

Dregabalin was introduced in 2004 as a more potent successor to the antiepileptic agent gabapentin (1). Since then, it has been widely used for the treatment of chronic pain and fibromyalgia (2). Its usefulness in controlling neuropathic symptoms and the apparent opioidsparing effect has been evaluated in clinical trials of acute pain (3-5). Our experience with this drug has also been consistent with reports in the literature, with significant improvements in acute pain management for carefully selected patients undergoing certain surgical procedures.

We report the perioperative course of three patients who received pregabalin and presented with significant postoperative respiratory depression. All three patients provided written consent for the publication of their case reports.

Case 1

\section{CASE PRESENTATIONS}

A 77-year-old woman was scheduled to undergo an elective craniotomy for excision of a parieto-occipital meningioma. Apart from the occasional headaches she was presently experiencing, she had no other neurological deficits related to this tumour. Her other medical issues
La dépression respiratoire postopératoire associée à la prégabaline : une série de cas et un algorithme de décision préopératoire

La prégabaline gagne en popularité pendant la période périopératoire en raison de son utilité dans le traitement de la douleur névropathique et de son effet apparent d'épargne des opiacés. Le présent rapport décrit l'évolution périopératoire de trois patients qui ont reçu de la prégabaline et ont souffert d'une importante dépression respiratoire pendant la période postopératoire. Tous trois ont consenti au compte rendu et à la publication de la présente série de cas. La première patiente était une personne âgée ayant une dysfonction rénale limite. Elle a subi un arrêt respiratoire pendant la période postopératoire suivant immédiatement une crâniotomie pour effectuer une excision tumorale. Le deuxième patient a souffert d'une grave dépression respiratoire 12 heures après avoir subi une anesthésie rachidienne pour arthroplastie, et on a constaté par la suite qu'il présentait une apnée obstructive du sommeil importante sur le plan clinique. Le troisième patient, une personne âgée autrement en santé qui prenait des benzodiazépines pour traiter son anxiété, a souffert d'un arrêt respiratoire à l'unité de soins postanesthésiques après une anesthésie sans histoire visant à traiter une décompression de la colonne lombaire. Tous ces patients ont réagi aux mesures de réanimation habituelles. Même si d'autres causes de dépression respiratoire ont été envisagées, il semble y avoir un lien entre la prégabaline et cette complication. Le présent article présente une brève analyse des données probantes relatives à l'utilisation périopératoire de la prégabaline. D'après leur expérience et les données probantes, les auteurs pensent que la prégabaline peut être utile pour prendre en charge la douleur aiguë chez des patients soigneusement sélectionnés qui subissent certaines opérations. Un algorithme clinique a été préparé pour orienter l'utilisation périopératoire de la prégabaline. Cet algorithme pourrait être utile pour accroître l'innocuité de l'utilisation périopératoire de prégabaline.

included systemic hypertension (controlled with diltiazem) and asymptomatic gastroesophageal reflux disorder treated with rabeprazole. Results from her laboratory investigations suggested mild renal dysfunction (creatinine $108 \mathrm{mmol} / \mathrm{L}$ ). She was anxious about her upcoming surgery. Because of her previous experience of limited benefit with benzodiazepines, she was prescribed pregabalin $75 \mathrm{mg} 2 \mathrm{~h}$ before receiving her anesthetic. In the operating room (OR), she did not demonstrate any signs of excessive sedation. Her anesthetic was induced with propofol $150 \mathrm{mg}$, lidocaine $100 \mathrm{mg}$, fentanyl $200 \mu \mathrm{g}$ and rocuronium $40 \mathrm{mg}$ (all intravenously [iv]), and it was maintained with tracheal intubation and desflurane using controlled ventilation. The surgeons resected a $2 \mathrm{~cm} \times 3 \mathrm{~cm}$ tumour from the frontoparietal cortex with minimal blood loss. During the course of anesthesia, which lasted $3 \mathrm{~h}$, her monitored parameters remained stable and she had received a total of fentanyl $250 \mu \mathrm{g}$ iv and hydromorphone $0.4 \mathrm{mg}$ iv. At the end of the procedure, after neuromuscular blockade reversal and awakening, tracheal extubation was performed. She was transferred to the postanesthesia care unit (PACU) where her immediate (brief) neurological examination was normal. Approximately 15 min later, she suddenly became nonresponsive and stopped breathing. Her oxygen 
saturation $\left(\mathrm{SpO}_{2}\right)$ fell to $90 \%$ and bag-mask ventilation was initiated. Although the $\mathrm{SpO}_{2}$ improved to $99 \%$ with this measure, there were still no spontaneous respiratory efforts and tracheal intubation was performed. The patient was given naloxone $0.2 \mathrm{mg}$. Within the next few minutes her respiratory rate and effort improved, and approximately $10 \mathrm{~min}$ after her respiratory arrest she met the standard criteria and her trachea was extubated. The rest of her recovery and postoperative course was unremarkable.

\section{Case 2}

A 67-year-old woman with osteoarthritis of the knees was scheduled for left total knee replacement. Preoperatively, she had mild asthma, controlled hypertension, gastroesophageal reflux disorder and mild depression. Apart from obesity (body mass index $46 \mathrm{~kg} / \mathrm{m}^{2}$ ), her anesthetic evaluation was unremarkable and her laboratory investigations suggested borderline renal dysfunction (creatinine $96 \mathrm{mmol} / \mathrm{L}$ ). Her medications included fluticasone and salbutamol inhalers, pantoprazole, citalopram, diltiazem and irbesartan. For her knee pain, she was using ibuprofen $400 \mathrm{mg}$ and oxycodone $5 \mathrm{mg}$ to $10 \mathrm{mg}$ (both taken as required). She rated her pain scores $3 / 10$ at rest and 6/10 with activity. Obstructive sleep apnea (OSA) was clinically suspected on her preoperative assessment, but no formal testing was recommended. In terms of premedication, she was advised to take acetaminophen $975 \mathrm{mg}$, celecoxib $400 \mathrm{mg}$ and pregabalin $75 \mathrm{mg}$ (all taken orally $2 \mathrm{~h}$ before surgery). In the OR, she received a spinal anesthetic with hyperbaric bupivacaine $12.5 \mathrm{mg}$, fentanyl $15 \mu \mathrm{g}$ and morphine $200 \mu \mathrm{g}$. During the uneventful surgery, which lasted $2 \mathrm{~h}$ and $15 \mathrm{~min}$, she also received a low-dose propofol infusion of $25 \mu \mathrm{g} / \mathrm{kg} / \mathrm{min}$ to $50 \mu \mathrm{g} / \mathrm{kg} / \mathrm{min}$.

In the PACU, she was given the next scheduled dose of acetaminophen $650 \mathrm{mg}$ and pregabalin $50 \mathrm{mg}$. She was prescribed patient-controlled analgesia (PCA) with hydromorphone (bolus $0.2 \mathrm{mg}$, basal infusion 0 $\mathrm{mg} / \mathrm{h}$, lockout interval $6 \mathrm{~min}$ and $1 \mathrm{~h} \mathrm{limit} 1.4 \mathrm{mg}$ ). She was also advised to continue the pregabalin $(50 \mathrm{mg}$ every $8 \mathrm{~h}$ [q8h]) with acetaminophen (650 mg q4h) and celecoxib (200 mg q12h). After the motor block from the spinal anesthesia had worn off in the PACU, she was transferred to the surgical ward continuing to be pain free. There, approximately 12 $\mathrm{h}$ after her spinal anesthetic was administered, she suddenly became diaphoretic, ashen-pale and then unresponsive. The nurse found her pulse to be feeble and her systolic blood pressure was $60 \mathrm{mmHg}$. The pulse oximeter could not record the $\mathrm{SpO}_{2}$ (reading "low"). Her respiration rate was also noted to be slow and shallow. A 'code' was called and as the resuscitation team arrived, she was given supplemental oxygen. The team initiated bag-mask ventilation. The PCA pump was carefully examined - she had not received any opioids since her anesthesia - she had made no attempts, no boluses and there was no inadvertent basal infusion. The team administered naloxone $(0.4 \mathrm{mg}$ iv $)$ and the patient responded to this treatment with improved respiration and some awakening. Her vital signs stabilized over the next $5 \mathrm{~min}$. She was conscious and oriented, but still drowsy. The team advised that continuous monitoring and supplemental oxygen be continued, and reduced the PCA hydromorphone dose to $0.1 \mathrm{mg}$. On postoperative day 1 (POD 1), the acute pain service re-evaluated the patient and provided a clinical diagnosis of OSA - history of snoring, daytime somnolence, observed pauses, hypertension, obesity and increased neck circumference. They suggested that the pregabalin be reduced to $25 \mathrm{mg}$ twice a day. Later that afternoon, the patient was still very drowsy and the acute pain service decided to discontinue pregabalin. Her pain scores $(0$ to 10$)$ were 3 at rest and 6 with movement, and she was tolerating her diet well. The acetaminophen and celecoxib were continued and, on POD 2, the PCA was discontinued. The remainder of the patient's stay was without event or incident.

\section{Case 3}

An 82-year-old woman with lumbar canal stenosis was scheduled to undergo lumbar decompression. She had low back pain and was on acetaminophen $325 \mathrm{mg}$ as required and diclofenac $50 \mathrm{mg} \mathrm{q} 12 \mathrm{~h}$. She also used quelizipine $25 \mathrm{mg}$ and trazadone $50 \mathrm{mg}$ at night for anxiety and lorazepam $0.5 \mathrm{mg}$ for night-time sedation. Her preanesthetic evaluation was unremarkable; she was advised to continue all of her medications, with pregabalin $50 \mathrm{mg}$ added as a premedication. In the $\mathrm{OR}$, the anesthesia was induced with propofol $100 \mathrm{mg}$, rocuronium $40 \mathrm{mg}$ and fentanyl $200 \mu \mathrm{g}$ (all iv), and was maintained with tracheal intubation and desflurane using controlled ventilation. During the surgery, which lasted approximately $70 \mathrm{~min}$, she received an additional $0.6 \mathrm{mg}$ iv hydromorphone and remained stable. After emergence, neuromuscular blockade reversal and extubation, she was transferred to the PACU. There, she remained conscious and oriented, and her vital signs were stable for the first $20 \mathrm{~min}$. After that, she suddenly stopped breathing and her $\mathrm{SpO}_{2}$ fell to $80 \%$. Bag-mask ventilation was initiated and the $\mathrm{SpO}_{2}$ increased to $98 \%$. As preparations for tracheal intubation and ventilation were made, she was given intravenous naloxone $(0.08 \mathrm{mg})$, after which spontaneous respiration returned. She then woke up and remained stable thereafter. Her pain medications were reviewed and pregabalin was omitted from the protocol. On POD 1, she was weaned off of her PCA and transitioned to oral medications. The rest of her hospital stay was without event or incident.

\section{DISCUSSION}

We have reported a series of three patients who experienced serious respiratory depression within the first $12 \mathrm{~h}$ following their anesthesia. Since the introduction of pregabalin in our centre, we have used lower doses of opioids, but are seeing an increase in the incidence of postoperative sedation and respiratory depression. These events and the accumulating experience of The Ottawa Hospital Acute Pain Service (Ontario) with this drug have led to the development of an algorithm to guide the rational preoperative use of pregabalin (summarized in Figure 1).

The United States Food and Drug Administration approves the use of pregabalin as an antiepileptic agent and for chronic pain experienced by patients with postherpetic neuralgia, fibromyalgia and diabetic peripheral neuropathy (1). In Europe, pregabalin is additionally approved for generalized anxiety disorder (6). In the perioperative period, studies showing the most promising results for pregabalin are in patients with neuropathic pain (3). This is a pain model in which pronociceptive mechanisms play an important role (7). These mechanisms have an equivalent in acute postoperative pain - pregabalin is very effective when the surgery is performed in the site of chronic pain (eg, joint arthroplasty for arthritis [8] and spine surgery for chronic back pain [9], etc). Other patients who may also benefit from perioperative pregabalin are those with chronic pain (fibromyalgia [10], etc), those who use opioids preoperatively or those who have previously experienced poorly controlled pain (11). Some encouraging results have also been seen in pain associated with multiple sclerosis (12), central pain syndromes (13) and spinal cord pain (14). Surgical models in which there is a perceived risk for chronic pain and patients who develop postoperative hyperalgesia (with or without opioids) may also benefit from pregabalin $(8,9)$.

The described relative contraindications for pregabalin include increasing age and renal dysfunction (1). Currently in our centre, patients younger than 50 years of age are rarely prescribed more than $75 \mathrm{mg}$ of pregabalin and we suggest decreasing this dose by $25 \mathrm{mg}$ for each decade above 50 years of age, so that patients older than 80 years do not receive any pregabalin preoperatively. The guidelines for decreasing the postoperative pregabalin dosing in patients with renal dysfunction are proportionately based on creatinine clearance: from $50 \mathrm{mg}$ q $8 \mathrm{~h}, 25 \mathrm{mg} \mathrm{q} 8 \mathrm{~h}, 25 \mathrm{mg}$ q $12 \mathrm{~h}$ to $25 \mathrm{mg}$ once daily for clearance values of greater than $60 \mathrm{~mL} / \mathrm{h}$, $30 \mathrm{~mL} / \mathrm{h}$ to $60 \mathrm{~mL} / \mathrm{h}, 15 \mathrm{~mL} / \mathrm{h}$ to $30 \mathrm{~mL} / \mathrm{h}$ and lower than $15 \mathrm{~mL} / \mathrm{h}$, respectively. For patients who are dialysis dependent, we prescribe pregabalin $25 \mathrm{mg}$ to $50 \mathrm{mg}$ twice a day, only on the days of dialysis. With the frequent association between renal dysfunction and pregabalin-induced respiratory depression in elderly patients, we recommend that renal function tests be performed before prescribing pregabalin and that dose adjustments be made. 


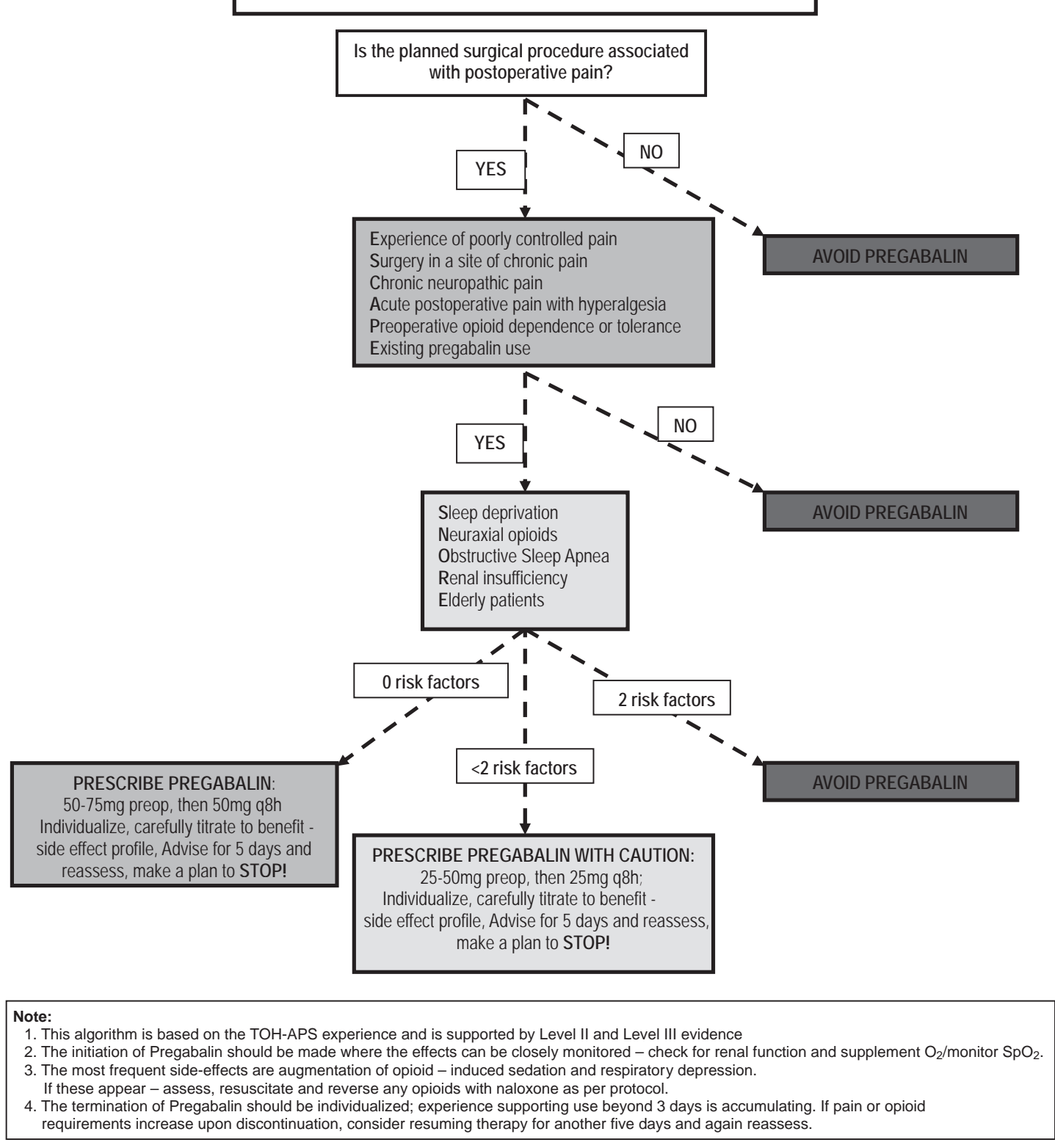

Figure 1) The Ottawa Hospital Acute Pain Service (TOH-APS; Ontario) preoperative algorithm for pregabalin use. Preop Preoperatively; q8h Every 8 h; $\mathrm{SpO}_{2}$ Oxygen saturation

The first patient in the present case series received pregabalin in lieu of benzodiazepine sedation for preoperative anxiety. In our opinion, her age, renal dysfunction (estimated creatinine clearance $31.8 \mathrm{~mL} / \mathrm{min}$ ) and the surgical procedure (craniotomy for brain tumour) are all conditions that require caution when using pregabalin. The second patient was given pregabalin as part of our standard multimodal analgesia protocol for joint arthroplasty surgery. She had clinically significant OSA and received a spinal anesthetic with intrathecal morphine, which probably played a major role in causing the respiratory depression. In the case of the third patient, there may have been an interaction between pregabalin and her other neuropsychiatric medications. She was also sleep deprived - she later revealed that she did not sleep much the previous night because she had to leave home very early in the morning. We have also seen this tendency in other patients and we predict that sleep deprivation will have to be specifically evaluated as another major risk factor for respiratory depression from pregabalin.
In patients with OSA, there is a known increased sensitivity to opioids (15). Sedation and drowsiness are the most frequently reported side effects of pregabalin $(8,16)$. Therefore, patients with OSA who receive both opioids and pregabalin perioperatively may be at increased risk for respiratory depression. When opioid-based neuraxial anesthetic techniques (epidurals and spinals) are planned, the role of preoperative pregabalin is debatable. These anesthetic techniques (17) themselves are associated with a higher incidence of respiratory depression and, therefore, adding pregabalin may further increase this side effect.

If patients have any one of these relative contraindications for the use of pregabalin, the preoperative dose can be reduced. If one risk factor increases in severity or if there is more than one risk factor, the chances of respiratory depression may increase because these risk factors appear to have an additive effect. When pregabalin is used perioperatively in patients with any of these risk factors, close monitoring for sedation is strongly recommended. Pregabalin 
probably should not be routinely prescribed for procedures that are not associated with significant postoperative pain. Indeed, there are clinical trials that have failed to demonstrate significant benefit from perioperative pregabalin (18-20).

Each of the patients described in the present series had other risk factors that may have contributed to the respiratory depression. As our perioperative experience with pregabalin increases and other cases of respiratory depression continue be detected, we believe that the contributory role of pregabalin cannot be denied. A common feature of the respiratory depression seen in all of these cases is its prompt reversal with naloxone. Expert opinion may criticize these cases as simply that of opioid overdose in opioid-sensitive patients.

We agree that the opioid is the main mechanism for respiratory depression in our cases. However, we propose that the addition of pregabalin's sedation to the scenario pushed the degree of opioidinduced respiratory depression over the clinically acceptable edge. Similar observations have been made when other sedative drugs, such as benzodiazepines, were combined with opioids (17).

The concepts that we have discussed above are summarized in Figure 1. Additional clinical trials and quality assurance studies will be required to validate this algorithm.

\section{REFERENCES}

1. Gajraj NM. Pregabalin: Its pharmacology and use in pain management. Anesth Analg 2007;105:1805-15.

2. Moore RA, Straube S, Wiffen PJ, Derry S, McQuay HJ. Pregabalin for acute and chronic pain in adults. Cochrane Database Syst Rev 2009; (3):CD007076.

3. Mathiesen O, Rasmussen ML, Dierking G, et al. Pregabalin and dexamethasone in combination with paracetamol for postoperative pain control after abdominal hysterectomy. A randomized clinical trial. Acta Anaesthesiol Scand 2009;53:227-35.

4. Agarwal A, Gautam S, Gupta D, Agarwal S, Singh PK, Singh U. Evaluation of a single preoperative dose of pregabalin for attenuation of postoperative pain after laparoscopic cholecystectomy. Br J Anaesth. 2008;101:700-4.

5. Mathiesen O, Jacobsen LS, Holm HE, et al. Pregabalin and dexamethasone for postoperative pain control: A randomized controlled study in hip arthroplasty. Br J Anaesth 2008;101:535-41.

6. Rickels K, Pollack MH, Feltner DE, et al. Pregabalin for treatment of generalized anxiety disorder: A 4-week, multicenter, doubleblind, placebo-controlled trial of pregabalin and alprazolam. Arch Gen Psychiatry 2005;62:1022-30.

7. Bee LA, Dickenson AH. Descending facilitation from the brainstem determines behavioural and neuronal hypersensitivity following nerve injury and efficacy of pregabalin. Pain 2008;140:209-23.

8. Buvanendran A, Kroin JS, Della Valle CJ, Kari M, Moric M, Tuman KJ. Perioperative oral pregabalin reduces chronic pain after total knee arthroplasty: A prospective, randomized, controlled trial. Anesth Analg 2010;110:199-207.

9. Burke SM, Shorten GD. Perioperative pregabalin improves pain and functional outcomes 3 months after lumbar discectomy. Anesth Analg 2010;110:1180-5.

10. Straube S, Derry S, Moore RA, McQuay HJ. Pregabalin in fibromyalgia: Meta-analysis of efficacy and safety from company clinical trial reports. Rheumatology (Oxford) 2010;49:706-15.

\section{CONCLUSIONS}

Pregabalin may be a useful component in multimodal analgesia for managing some surgical models of acute pain (ie, in cases for which pronociceptive mechanisms lead to perioperative hyperalgesia). A serious side effect appears to be augmentation of opioid-induced sedation and respiratory depression. This is more frequently seen in patients who are elderly, have renal dysfunction, OSA or those who receive neuraxial opioids. We have developed a clinical algorithm for pregabalin and believe that it may be helpful in increasing the safety of perioperative pregabalin use.

POSTER PRESENTATION: This research was presented as a poster at the International Anesthesia Research Society Annual Meeting held in Honolulu, Hawaii, March 20 to 23, 2010.

CONFLICTS OF INTEREST AND SOURCES OF SUPPORT:

Dr Penning has received honoraria from Pfizer for continuing medical education presentations on acute pain.

11. Gilron I. Gabapentin and pregabalin for chronic neuropathic and early postsurgical pain: Current evidence and future directions. Curr Opin Anaesthesiol 2007;20:456-72.

12. Pöllmann W, Feneberg W. Current management of pain associated with multiple sclerosis. CNS Drugs 2008;22:291-324.

13. Vranken JH, Dijkgraaf MG, Kruis MR, van der Vegt MH, Hollmann MW, Heesen M. Pregabalin in patients with central neuropathic pain: A randomized, double-blind, placebo-controlled trial of a flexible-dose regimen. Pain 2008;136:150-7.

14. Tzellos TG, Papazisis G, Amaniti E, Kouvelas D. Efficacy of pregabalin and gabapentin for neuropathic pain in spinal-cord injury: An evidence-based evaluation of the literature. Eur J Clin Pharmacol 2008;64:851-8.

15. Seet E, Chung F. Management of sleep apnea in adults - functional algorithms for the perioperative period: Continuing Professional Development. Can J Anaesth 2010;57:849-64.

16. Peng PW, Li C, Farcas E, et al. Use of low-dose pregabalin in patients undergoing laparoscopic cholecystectomy. Br J Anaesth 2010;105:155-61.

17. American Society of Anesthesiologists Task Force on Neuraxial Opioids; Horlocker TT, Burton AW, Connis RT, et al. Practice guidelines for the prevention, detection, and management of respiratory depression associated with neuraxial opioid administration. Anesthesiology 2009;110:218-30.

18. Jokela R, Ahonen J, Tallgren M, Haanpää M, Korttila K. A randomized controlled trial of perioperative administration of pregabalin for pain after laparoscopic hysterectomy. Pain 2008;134:106-12.

19. Paech MJ, Goy R, Chua S, Scott K, Christmas T, Doherty DA. A randomized, placebo-controlled trial of preoperative oral pregabalin for postoperative pain relief after minor gynecological surgery. Anesth Analg 2007;105:1449-53.

20. Chang SH, Lee HW, Kim HK, Kim SH, Kim DK. An evaluation of perioperative pregabalin for prevention and attenuation of postoperative shoulder pain after laparoscopic cholecystectomy. Anesth Analg 2009;109:1284-6. 


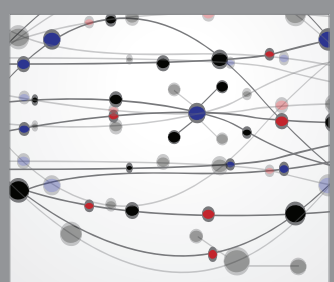

The Scientific World Journal
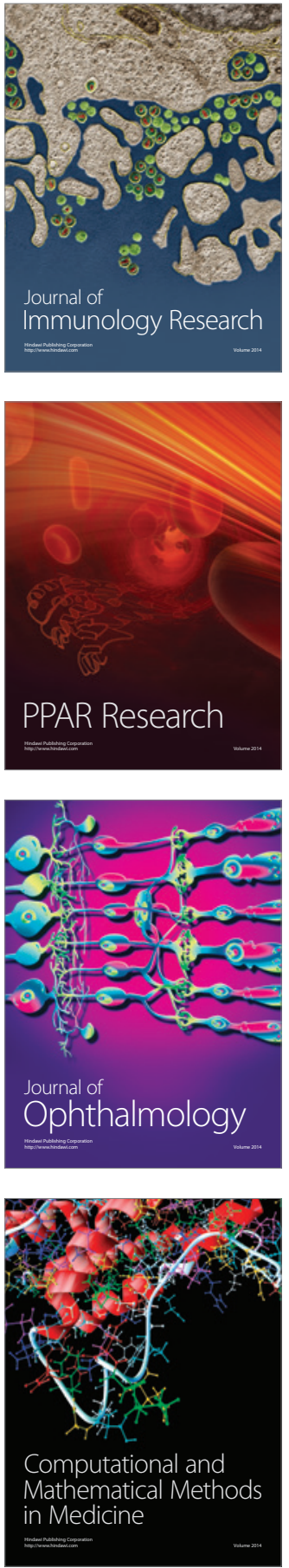

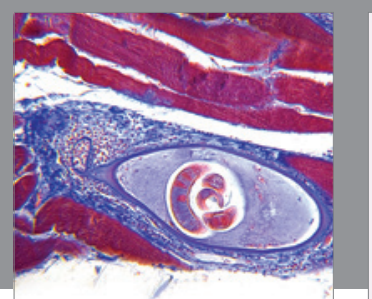

Gastroenterology Research and Practice

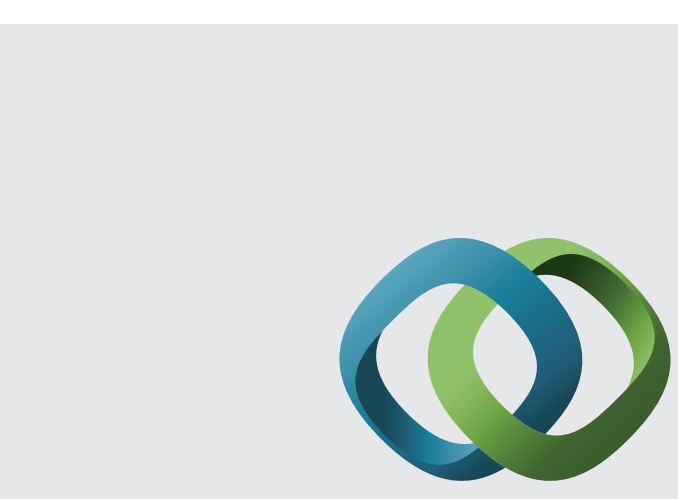

\section{Hindawi}

Submit your manuscripts at

http://www.hindawi.com
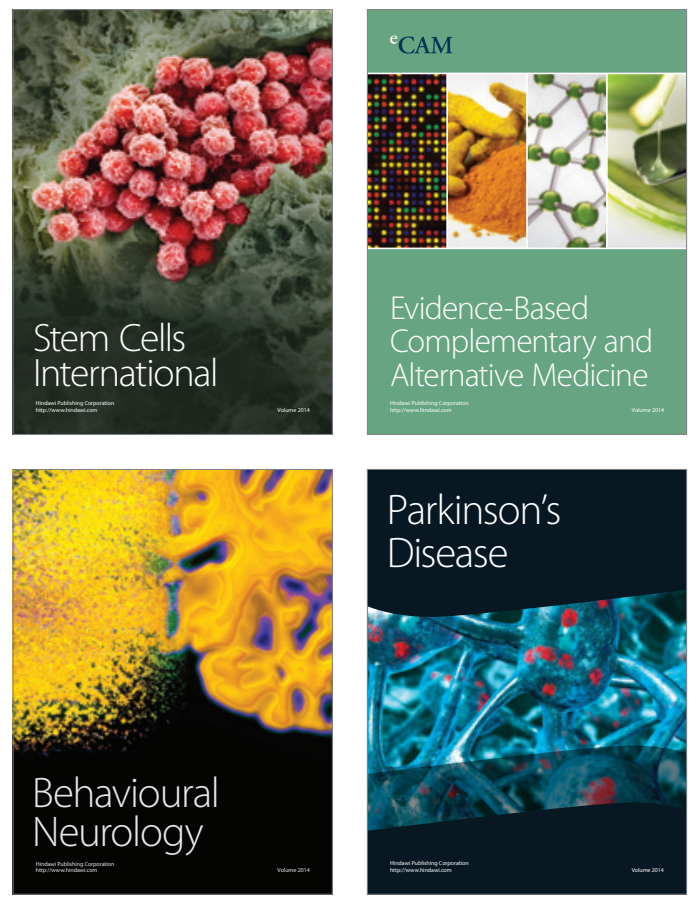
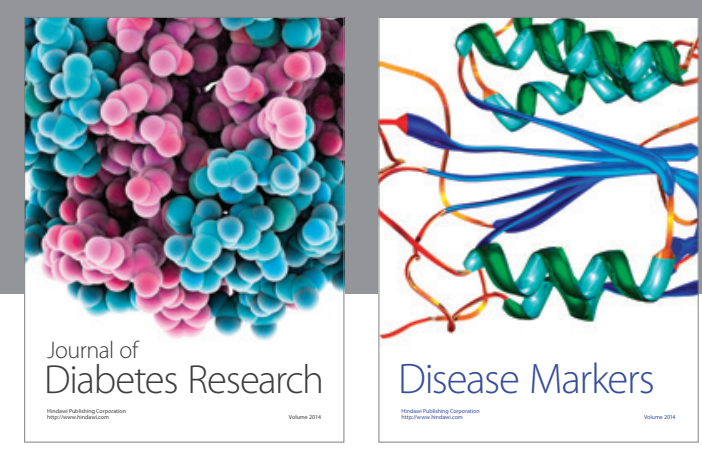

Disease Markers
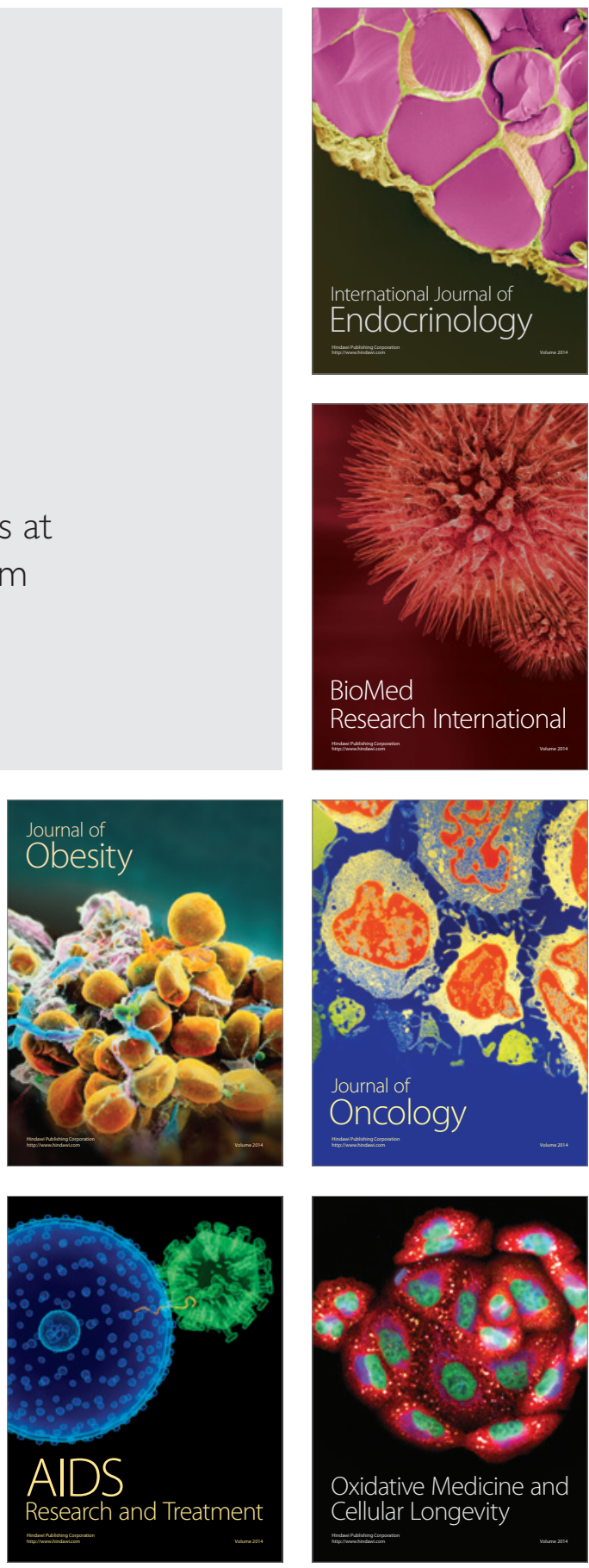